\title{
Samhandling mellom allmennleger og apotek ved korreksjon av resepter
}

\begin{abstract}
Sammendrag
Bakgrunn. Apotekfarmasøyter intervenerer ved rundt $2 \%$ av reseptordinasjoner for å kunne ekspedere dem forsvarlig. Vi ønsket å undersøke hvordan allmennleger og apotekfarmasøyter praktisk håndterer og dokumenterer ulike typer reseptintervensjoner og hva de anser som god praksis på området.
\end{abstract}

Materiale og metode. To fokusgrupper med totalt fem allmennpraktiserende leger, fem apotekfarmasøyter og to legesekretærer ble rekruttert i to ulike geografiske områder. Fokusgruppene tok utgangspunkt i 12 reelle eksempler fra seks ulike kategorier av reseptintervensjoner fra en tidligere studie i apotek. Utsagnene fra fokusgruppene ble sammenfattet og tematisert.

Resultater. Legene og apotekfarmasøytene hadde varierende praksis for håndtering av farmasøytenes reseptintervensjoner. Begge parter forventet at den andre dokumenterte reseptintervensjonene og registrerte selv kun i begrenset grad. Legenes elektroniske journalsystemer er ikke tilrettelagt for registrering av reseptintervensjoner. Manglende interne retningslinjer førte til individuell praksis hos både apotekfarmasøytene og legene. Generelt prioriterte farmasøytene legekontakt og tilbakemelding av klinisk relaterte intervensjoner. Legene ønsket tilbakemeldinger oftere enn farmasøytene tilbød.

Fortolkning. Det bør utvikles felles retningslinjer for samhandling, prioritering og dokumentasjon av reseptintervensjoner i apotek og på legekontor. Det er behov for en fremtidsrettet kommunikasjonsløsning som ivaretar behovet for rask toveiskommunikasjon og som utnytter mulighetene som ligger i elektroniske løsninger.
Ingunn Mandt*

ingunnma@online.no

Anne Marie Horn t

Anne Gerd Granås**

Apoforsk - Institutt for apotekforskning

Postboks 5070 Majorstuen

0301 Oslo

\section{* Nåværende adresse \\ Apotek 1 Kirkenær \\ 2260 Kirkenær}

** Nåværende adresse Senter for farmasi

Institutt for samfunnsmedisinske fag

Universitetet i Bergen

Resepter må ha god kvalitet for å sikre at apotek utleverer ordinerte legemidler med riktig informasjon til pasienten. Ufullstendige eller uriktige opplysninger om legemiddelbruk representerer en helserisiko for pasientene. Dagens apotekforskrift angir at problemer skal oppklares i tilknytning til reseptekspedisjonene, men retningslinjer mangler for dokumentasjon av reseptintervensjoner, prioritering av henvendelser og for eventuell delegering av oppgaver (1).

Reseptintervensjoner i apotek innebefatter endringer som følge av forskrivningsfeil (feil legemiddel, styrke, administrasjonsform og dosering) og endringer som følge av manglende opplysninger (ikke angitt legemiddel, styrke, administrasjonsform eller dosering) (2). Reseptintervensjoner forebygger feil ved legemiddelbruk hos pasienter som har ansvar for sine medisiner selv og for pasienter der hjemmetjenesten har medisineringsansvaret. Intervensjonsårsakene spenner fra forskrivningsfeil og problemstillinger knyttet til legemiddelbehandlingen til spørsmål om trygderefusjon og formelle reseptfeil (2-5).

I 2007 ble det ekspedert resepter med vel 37 millioner ordinasjoner i norske apotek (6). Det er anslått at apotekfarmasøyter endrer eller oppklarer forhold ved ca. $2 \%$ av alle ordinasjoner apotekene mottar, hvorav ca.17\% kan være av klinisk betydning (2). Overfører man intervensjonstallene, indikerer dette at over 100000 reseptintervensjoner med kliniske problemstillinger ble gjort på norske apotek i 2007. Andelen av reseptintervensjoner som meldes tilbake til legen, er ikke kjent. Resepter fra leger i allmennpraksis er mest berørt, siden allmennleger står for $80 \%$ av alle legemiddelordinasjoner.

Problemer knyttet til overføring av legemiddelinformasjon har fått stor oppmerksomhet innenfor sykehussektoren, ved skifte av omsorgsnivå og etter hvert også innen primærhelsetjenesten (7-9). Måten apotekfarmasøyter $\mathrm{og}$ allmennleger håndterer $\mathrm{og}$ dokumenterer reseptintervensjoner med dagens hjelpemidler er så langt oss bekjent ikke tidligere beskrevet.

Det er behov for bedre ordninger for hvordan og når tilbakemeldinger om legemiddelbruk mellom forskrivende lege, apotek og pasient skal finne sted. Den farmasøytiske vurdering ved reseptekspedisjon er en siste kvalitetskontroll før pasienten overtar ansvaret for å bruke legemidlene. Allmennleger og apotek vil i nær fremtid bli knyttet til elektroniske kommunikasjonsløsninger på tvers av behandlingssted og behandlingsnivå gjennom elektroniske resepter (eResept) $(10,11)$. Foreløpig er systemet ikke lagt til rette for en online-kommunikasjon om reseptintervensjoner.

Hensikten med denne studien har vært å undersøke hvordan leger i primærhelsetjenesten og apotekfarmasøyter i praksis kommuniserer om reseptintervensjoner, hvordan de håndterer og dokumenterer reseptintervensjoner på sine respektive arbeidsplasser og hva begge parter anser som god praksis på området.

\section{Materiale og metode}

Undersøkelsen er en kvalitativ studie basert på to fokusgrupper, en $\mathrm{i}$ et landdistrikt $\mathrm{i}$ Nord-Norge og en i et bymessig område på Østlandet. Fem allmennpraktiserende leger (to kvinner og tre menn) fra fem legekontor med 1-3 leger, fem apotekfarmasøyter (fire kvinner og en mann) fra fem apotek i samme distrikt som legekontorene og to legesekretærer (kvinner) deltok. Med unntak av én legesekretær og én lege fra samme legekontor, ble informantene rekruttert fra hvert sitt arbeidssted ved hjelp av snøballteknikk, det vil si at de først rekrutterte deltakerne

\section{Hovedbudskap}

- Legene ønsker flere tilbakemeldinger om uklarheter ved resepter enn farmasøytene gir

- Begge parter tror den andre dokumenterer mer enn det som faktisk skjer

- Samhandling og håndtering av reseptintervensjoner i apotek og på legekontor er mangelfullt regulert i eksisterende lovgivning 
fant nye deltakere. Deltakerne hadde 2-30 års arbeidserfaring. Gruppeintervjuene ble holdt i konferanserom og varte $\mathrm{i}$ ca. to timer. Moderatoren (IM) som ledet begge intervjuene, kjente emnet fra mange års praksis som apoteker og var assistert av en forskerkollega. Intervjuene ble strukturert rundt reelle, anonymiserte eksempler fra seks intervensjonskategorier av problemer som hadde ført til reseptintervensjoner i apotek (ramme 1). Fokusgruppedeltakerne svarte skriftlig for hvert av de seks eksemplene om kontakt mellom apotek og legekontor burde tas før eller etter utlevering av legemidlene eller om kontakt var unødvendig. Etter gjennomgang av intervensjonskategoriene ble fokusgruppene bedt om å diskutere mer generelt hvordan praktisk kommunikasjon mellom apotek og legekontor kunne organiseres på en god måte (ramme 2)

Det ble gjort elektronisk lydopptak som ble transkribert ordrett. Hyppig forekommende og sammenfallende synspunkter ble identifisert og samlet og meningsinnholdet fortettet til korte, beskrivende utsagn (12). Legesekretærenes og legenes utsagn ble slått sammen når de beskrev hvilke interne rutiner legekontorene fulgte. Utsagn og utskrifter ble drøftet med forskerkollegene fra gruppeintervjuene.

Informantenes utsagn om funksjonaliteten av elektroniske journalsystemer med hensyn til oppfølging av reseptintervensjoner på legekontoret ble oppsummert og presentert av hovedforfatter i møter med tre journalsystemleverandører (Infodoc, Profdoc Norge og Hove Medical Systems) høsten 2006. Journalsystemleverandørene forklarte funksjonaliteten i sine respektive systemer og bekreftet eller korrigerte utsagnene fra deltakerne i fokusgruppene.

\section{Resultater}

Legenes håndtering av farmasøytenes intervensjonsmeldinger

Legene og legesekretærene så på farmasøytenes kritiske vurdering av reseptene ved ekspedisjon som kvalitetssikringstiltak. Farmasøytenes forslag og problemløsninger, slik de ble presentert i eksemplene og i diskusjonene i gruppene, ble stort sett akseptert av legene. Legene beskrev ulik praksis for registrering og dokumentasjon av mottatte meldinger om reseptintervensjoner. De ønsket i større grad enn det farmasøytene tilbød melding om intervensjoner samt tilbakemelding før utlevering av legemidlene. I landdistriktsgruppen oppga legen og legesekretæren i ett område at de syntes tilbakemeldingspraksisen på de lokale apotekene var god.

Bare et utvalg av intervensjonsmeldingene ble registrert i de elektroniske journalsystemene på legekontorene. Legene opplyste at de prioriterte registrering av endringer som gjaldt faste medisiner og riktig pasientidentitet. Intervensjonsmeldinger som hadde liten konsekvens for pasientene, kunne bli nedprioritert, og registrering ble i ulik grad delegert til legesekretærer. Som begrunnelse for varierende praksis oppga legene og legesekretærene at de elektroniske journalsystemene ikke var tilrettelagt for rask oppfølging og registrering av endringer i etterkant av forskrivningene. De fortalte at generelle og tidsavgrensede meldinger, for eksempel ved leveringsvansker, var vanskelig å registrere i de individtilpassede journalsystemene. Både legene og legesekretærene i fokusgruppene antok at dokumentasjon av reseptintervensjonene fantes på apoteket. Under tidspress kunne de derfor unnlate å registrere meldinger.

\section{Farmasøytenes håndtering \\ av intervensjonsmeldinger}

Farmasøytene hadde individuell praksis i forhold til når de kontaktet forskriver og når de dokumenterte intervensjonene $\mathrm{i}$ apotekenes kvalitetssystemer. De meldte et utvalg av reseptintervensjonene tilbake til legen eller legekontoret og prioriterte kontakt med legen ved klinisk relaterte intervensjoner, spesielt $i$ vurdering av resepter til barn. Tilbakemeldinger om tekniske og formelle feil, logistikkproblemer og endringer gjort for å bedre pasientens etterlevelse av behandlingen ble nedprioritert. Farmasøytene i fokusgruppene forventet at intervensjonsmeldingene ble registrert og journalført på legekontoret.

Som begrunnelse for varierende og individuell praksis om intervensjonsmeldinger til legen oppga farmasøytene tidspress og få eller manglende interne retningslinjer for oppfølging av intervensjoner. Unntaket var farmasøytene fra området der legen og legesekretæren var godt fornøyd med tilbakemeldingene, som fortalte om en samordnet praksis.

\section{Dialog om reseptintervensjoner}

Farmasøytene, legene og legesekretærene så behov for to typer av kommunikasjonsløsninger mellom farmasøyt og lege: Et raskt system for direkte kontakt og avklaring av problemstillinger i umiddelbar tilknytning til reseptekspedisjonene og et system for skrift$\mathrm{lig} /$ passiv orientering i etterkant. Legene vektla at intervensjonsmeldinger enkelt burde kunne kobles til den aktuelle reseptekspedisjon eller pasient i den elektroniske journalen. En lege påpekte at skriftlige meldinger burde egne seg for direkte overføring til journalsystemet (skanning).

Alle deltakerne vektla at total tidsbruk ikke måtte øke ved endring av rutiner. En fokusgruppe synliggjorde at stabile lokalmiljøer la til rette for tillit og god kommunikasjon mellom legekontor og apotek og befordret uformelle avtaler. Basert på erfaringene sine oppsummerte deltakerne noen anbefalinger for organisering av kommunikasjon om reseptintervensjoner innenfor dagens system (ramme 2 ).

\section{Elektroniske journalsystemer}

Legene og legesekretærene i fokusgruppene hadde erfaring med tre ulike journalsyste-

\section{Ramme 1}

Fokusgruppene ble presentert for to problemstillinger innenfor seks reseptintervensjonskategorier: Legemidlet er ikke tilgjengelig, legemiddelvalg/dosering må oppklares, andre kliniske problemstillinger, administrasjonsform/legemiddelform bør endres for å bedre etterlevelse av behandling, refusjonsproblematikk og formelle feil/lav reseptkvalitet (4). Fokusgruppene ble vist to eksempler fra hver intervensjonskategori. Eksemplene som er vist illustrerer intervensjonskategorien legemiddelvalg/dosering må oppklares.

Eksempel 1

Første ekspedisjon av blå resept fra fastlege. Til barn født 2002:

Lamictal $50 \mathrm{mg} 50$ tabletter $\times 8$. Mot

epilepsi. 2 tabletter morgen og kveld. Apoteket har ikke historikk. Pårørende (bestemor) vet bare at forrige resept var utskrevet av sykehuslege. Farmasøytens problemstilling: Er dosering riktig?

Eksempel 2

Første ekspedisjon av blå resept fra fastlege, til mann født 1922:

Lasix ret $30 \mathrm{mg} 100$ tabletter 1 tablett daglig.

Mannen leverer også eldre blå resept:

Furix 40 mg 100 tabletter 1 tablett daglig.

Apotekets historikk sier at mannen har brukt Furix 40 mg lenge.

Mannen mener han skal bruke begge legemidler.

Farmasøytens problemstilling: Bør dobbeldoseringen sjekkes med legen?

Hver intervensjonskategori ble beskrevet av moderator i kort innledning. Deretter ble de to eksemplene innen kategorien presentert. Samme spørsmålsrekke ble gjentatt for alle de 12 eksemplene:

1 a) Vil du som farmasøyt kontakte lege ved tilsvarende problemstillinger?

b) Ønsker du som lege å bli kontaktet hvis farmasøyten står overfor tilsvarende problemstillinger?

Forutsatt at farmasøyten tar kontakt:

2 Hvordan blir henvendelser fra apoteket om slike problemstillinger behandlet på legekontoret?

3 a) Hvordan blir en henvendelse fra apoteket om denne typen problemstillinger fulgt opp (registrert/endret/dokumentert) på legekontoret?

b) Hvilke opplysninger er vesentlig å få ved henvendelse om denne typen reseptintervensjon?

c) Hvilke data bør apoteket oppbevare etter en slik intervensjon?

mer i allmennpraksis. De syntes journalsystemene hadde ulik funksjonalitet og ulike svakheter på legemiddelområdet, men noen problemtyper gikk igjen. Problemstillingene 


\section{Ramme 2}

Oppsummering av fokusgruppenes synspunkter på god praktisk samhandling og kommunikasjon lokalt ved reseptintervensjoner, basert på tre generelle spørsmål:

1. Kan praktisk kommunikasjon om reseptintervensjoner differensieres?

2. Hvordan kan kommunikasjon mellom apotek og legekontor best organiseres?

3. Hva er vesentlig informasjon i kommunikasjonen mellom apotek og legekontor om reseptintervensjoner?

Ved saker som krever rask, toveis kontakt i tilknytning til reseptekspedisjon, bør telefon, ev. faks brukes, så lenge apotekene er utenfor Helsenettet. Kommuniser om én sak av gangen. Kommunikasjon mellom apotek og legekontor må prioriteres begge veier. Den må følges opp praktisk, for eksempel med prioritert telefaks-og telefonlinje.

Meldinger til orientering for lege/legekontor kan sendes som telefaks, eventuelt e-post (personvern må ivaretas). En standardmal, designet både for dokumentasjonsformål og skriftlig kommunikasjon mellom apotek og legekontor, kan være effektivitsfremmende.

Lokal avtale om samhandlingsrutiner for aktuelle problemstillinger kan bidra til effektivisering og trygg praksis.

som informantene beskrev, var så like for de forskjellige systemer at de her gjengis samlet: Det finnes mange valgmuligheter for oppdatering av legemiddelregistrene i journalsystemene, men ingen sikrer at registrene alltid er à jour. Oppdatering av legemiddelregisteret fører ikke automatisk til oppdatering av aktuelle legemiddeldata i alle andre moduler. Legemiddelregisteret og andre moduler i systemene, for eksempel legemiddelkortet, kommuniserer ikke alltid med hverandre: Korreksjoner som blir gjort etter meldinger fra apoteket, forhindrer ikke automatisk gjenbruk av gamle, feilaktige data ved fornying av resept. Tidsbegrenset informasjon og gruppemeldinger, for eksempel om leveringsvansker, kan ikke enkelt knyttes til enkeltprodukter og enkeltpasienter. Korrekte standardinnstillinger i journalsystemene kan overstyres. I intervjuer med representanter for de tre aktuelle systemleverandørene ble det bekreftet at dagens elektroniske journalsystemer kunne ha slike svakheter som informantene beskrev.

\section{Diskusjon}

I vår studie ble bare et utvalg av mottatte intervensjonsmeldinger registrert i de elektroniske pasientjournalene på legekonto- rene. I en tidligere studie av interne apotekrutiner fant vi at sporadisk dokumentasjon og få meldinger til forskriver gikk igjen ved bytte av legemiddel på grunn av logistikkproblemer, ved endring av administrasjonseller legemiddelform og ved formelle og tekniske reseptfeil (4). Funnene indikerer at dokumentasjon av de samme intervensjonstypene nedprioriteres hos begge parter, fordi både leger og farmasøyter baserte seg på at den andre part dokumenterte. Dette kan bidra til utilsiktet variasjon og fare for hull i informasjonen om legemiddelforskrivningen til enkelte pasienter.

Legene i vår studie ville ha tilbakemelding om reseptintervensjoner oftere enn farmasøytene tilbød. Apotekfarmasøyter arbeider under tidspress og tenderer til å redusere antall henvendelser til legekontor hvis kommunikasjonsløsningene oppleves som dårlig tilpasset arbeidssituasjonen (13). Mer systematisk kommunikasjon om reseptintervensjoner enn dagens praksis vil antakelig øke antall henvendelser fra apotek til legekontor og kan bli tidkrevende for begge parter. Våre informanter var enige om at personlig kontakt ofte var nødvendig ved reseptintervensjoner, men at ikke alle typer reseptintervensjoner hadde hastestatus.

Fokusgruppene beskrev at de hadde utviklet ulike prioriteringer ved håndtering av reseptintervensjoner på det enkelte apotek og legekontor. Gruppen fra landdistriktet synliggjorde at steder med få og stabile aktører kan ha velfungerende uformelle systemer. Utviklingen i senere år med stor økning i antall apotek vil kunne gi mindre stabilitet lokalt (6). Avtaler som definerer rutiner og samhandling mellom apotek og legekontor lokalt, slik som fokusgruppedeltakerne skisserer, kan optimalisere praksis på kort sikt. Vi ser behov for retningslinjer for håndtering og dokumentasjon av reseptintervensjoner på apotek og legekontor. Den eksisterende lovgivningen er svært generell på dette punktet, både for apotek- og legepraksis (14-17).

Meldingssystemene bør også tilpasses moderne kommunikasjonsmidler. Det kommende e-reseptsystemet vil gi muligheter for korte tilbakemeldinger fra farmasøyt til rekvirent via den elektroniske reseptbanken (reseptformidleren) (18), og kan forhåpentligvis overta lavhastighetskommunikasjon og dokumentasjon i disse tilfellene.

Det er blitt fremholdt at inkorporering av elektronisk reseptoverføring i journalsystemene vil redusere feil og behov for korreksjoner på reseptene, blant annet gjennom innføring av et felles oppdatert legemiddelregister på legekontor og i apotek (18). En svensk studie av elektroniske resepter viser at formelle feil og ufullstendige data reduseres ved bruk av elektroniske resepter. Den totale feilfrekvensen går da ned, men frekvensen av klinisk betydningsfulle feil reduseres ikke (11).

Hastekommunikasjon er $\mathrm{i}$ dag henvist til telefon og telefaks, fordi apotekene ikke er integrert $\mathrm{i}$ et sikkert informasjonsutvekslingssystem med legene, som for eksempel Norsk Helsenett. Erfaringene fra Sverige, der det er utstrakt bruk av elektroniske resepter, viser at behovet for rask toveis kontakt mellom legekontor og apotek ikke blir mindre med elektronisk overføring (11), delvis fordi eReseptsystemet ikke åpner for aktiv kommunikasjon i «nåtid» (18). Personlig kontakt blir aldri avleggs, men det er opplagte svakheter i et system basert på muntlighet og med variabel tilgjengelighet.

Legene og legesekretærene mente at dagens elektroniske journalsystemer både bidro til feil og hemmet korreksjon i etterkant av intervensjoner. Testing av journalsystemenes funksjonalitet mot apotek kan føre til at man får rettet opp noen slike problemer.

Praktisk kommunikasjon ved reseptintervensjoner var et uvant tema for deltakerne $\mathrm{i}$ fokusgruppene. Fokusgrupper egner seg generelt til å synliggjøre sammenhenger og arbeidsprosesser som ikke er kjent og systematisert, og dette synes vi ble oppnådd. Vi fikk eksempler på praksis på et område som er lite beskrevet tidligere (19). Deltakere ble rekruttert med snøballmetode, noe som kan gi likesinnede deltakere. Synspunkter som fremkommer i fokusgrupper tenderer også til å være det man antar andre kan akseptere, og profesjonsblandingen kan ha dempet deltakernes synspunkter. Det kom likevel frem noen forskjeller, for eksempel mellom bygruppen og landdistriktsgruppen. Materialet ble analysert med den hensikt å synliggjøre hva det var konsensus om, fordi et delmål for prosjektet var å vise hva deltakerens så på som god praksis. Vi kunne analysert materialet med vekt på andre aspekter, men valgte å avgrense prosjektet. Funnene gir grunnlag for å generere hypoteser, og en oppfølging med utdyping av funnene hos flere grupper kunne vært ønskelig.

\section{Konklusjon}

Det bør utvikles retningslinjer for samhandling, prioritering og dokumentasjon av reseptintervensjoner i apotek og på legekontor. Behovet for rask toveis kommunikasjon mellom lege og apotekfarmasøyt knyttet til klinisk relaterte reseptintervensjoner vil være der også ved innføring av elektroniske resepter. Det er behov for en fremtidsrettet kommunikasjonsløsning som varetar dette.

Takk til deltakerne i fokusgruppene og medarbeiderne hos journalleverandørene, til Anders Ekedahl, Apoteket $A B$ og Svein Håvik, Apoforsk, for diskusjon underveis, til Janecke Thesen og Per Stensland ved Universitetet i Bergen, for råd og innspill i startfasen og Tone Bjerke, Apoforsk, for sekretærhjelp.

Oppgitte interessekonflikter: Ingen 


\section{Litteratur}

1. FOR 2001-02-26 nr. 178. Forskrift om apotek lapotekforskriften). http://lovdata.no/for/sf/ho/xo20010226-0178.html (30.4.2009).

2. Haavik S, Horn AM, Mellbye KS et al. Forskrivningsfeil - omfang og oppklaring. Tidsskr Nor Lægeforen 2006; 126: 296-8

3. Hawksworth GM, Corlett A, Wright D et al.Clinical pharmacy interventions by community pharmacists during the dispensing process. Br J Clin Pharmacol 1999; 47: 695-700.

4. Mandt I, Horn AM, Granas AG. Endringer av resepter i apotekene. Tidsskr Nor Lægeforen 2006; 126 : $1754-5$.

5. Rupp MT, DeYoung M, Schondelmeyer SW. Prescribing problems and pharmacist interventions in community practice. Med Care 1992; 30: 926-40.

6. Apotek og legemidler 2007. Bransjestatistikk om apotekenes virksomhet og rammevilkår. Oslo: Apotekforeningen, 2007.

7. Viktil KK. Drug-related problems in hospitalized patients. A major challenge in current medicine. Doktorgradsavhandling. Oslo: Det medisinske fakultet, Universitetet i Oslo, 2007.

8. Bakken K, Larsen E, Lindberg PC et al. Mangelfull kommunikasjon om legemiddelbruk i primærhelsetjenesten. Tidsskr Nor Lægeforen 2007; 127 1766-9.

9. Rognstad S, Straand J. Vet fastlegen hvilke medisiner hjemmesykepleien gir pasientene? Tidsskr Nor Lægeforen 2004; 124: 810-2.

10. Grimsmo A. Elektronisk resept - uten bivirkninger? Tidsskr Nor Lægeforen 2006; 126: 1740-3.

11. Astrand B, Montelius E, Petersson G et al. Assessment of ePrescription quality: an observational study at three mail-order pharmacies. BMC Med Inform Decis Mak 2009; 9: 8

12. Kvale S. Det kvalitative forskningsintervju. Oslo: Gyldendal, 2005

13. Mandt I, Horn AM, Ekedahl A et al. Community pharmacists prescription intervention practices exploring variations in practice in Norwegian pharmacies. Res Social Adm Pharm 2009; e-publisert 29.7.2009

14. FOR-1998-04-27-455. Forskrift om rekvirering og utlevering av legemidler fra apotek. www.lovdata.no/for/sf/ho/xo-19980427-0455.html (30.4.2009).

15. FOR-2000-12-21-1385. Forskrift om pasientjournal. www.lovdata.no/for/sf/ho/xo-200012211385.html (30.4.2009).

16. LOV-2000-06-02-39. Lov om apotek. www.lovdata.no/all/hl-20000602-039.htlm (30.4.2009).

17. LOV-1999-07-02-64. Lov om helsepersonell m.v. www.lovdata.no/all/hl-19990702-064.html (30.4.2009)

18. Heibø M. Elektroniske resepter vurdert mot pasientgruppers behov. Masteroppgave. Trondheim: Institutt for telematikk, NTNU, 2006.

19. Stewart DW, Shamdasani PN. Focus groups theory and practice. London: SAGE Publications, 1990.

Manuskriptet ble mottatt 17.10. 2008 og godkjent 30.4. 2009. Medisinsk redaktør Michael Bretthauer. 